\section{Utilizing existing legal frameworks to implement fisheries management in the arctic}

As climate change contributes to accelerated melting of sea ice in the Arctic Ocean, areas that were previously off-limits to fishing will become accessible. While there are currently no internationally-agreed fishing regulations in the high seas of the Arctic, there is an effective moratorium on commercial fishing thanks to the non-binding "Oslo Declaration" (Declaration concerning the Prevention of Unregulated High Seas Fishing in the Central Arctic Ocean, from July 2015). The author investigates existing legal mechanisms which could be used to regulate an international Arctic fishery should commercial fishing begin.

Currently, the Arctic Five (Canada, Denmark/Greenland, Norway, the Russian Federation, and the United States) plus Five (Iceland, the EU, China, South Korea, and Japan) are negotiating an agreement for fisheries management in the Central Arctic Ocean. The draft text, which has not reached consensus yet ${ }^{*}$, surprisingly does not seek to establish a regional fisheries management organization for this area. But, the Arctic $5+5$ have agreed "to continue the moratorium on fishing on the high seas of Central Arctic until there is scientific evidence concerning sustainable fishing in the area."

The draft agreement further states, "the parties shall take measures consistent with international law to deter the activities of vessels entitled to fly the flags of non-parties that undermine the effective implementation of this Agreement." But what measures "consistent with international law' could member states adopt?

\section{Port State Control}

The UN Convention on the Law of the Sea (UNCLOS) establishes one of the best mechanisms for addressing illegal, unreported and unregulated (IUU) fishing on the highseas: port State control. While on the high seas, the flagged State has exclusive jurisdiction over the vessel. However, while at port, the coastal State receives this authority. The 2009 Port State Measures Agreement (PSM Agreement) which recently came into effect has energized discussion on using this port-based jurisdiction to manage IUU fishing. The author notes:

f 6 Indeed, there is no doubt that the port State can enforce not only its own national laws but also its international obligations on foreign fishing vessels in its ports, including the landing, selling, and even transportation of fish caught illegally on the high seas (residual port-State jurisdiction). This was supported by both the 1993 Compliance Agreement and was also expressly acknowledged in the Fish Stocks Agreement and the more recent PSM Agreement."

The Fish Stocks Agreement specifically mentions:

6S States may adopt regulations empowering the relevant national authorities to prohibit landings and transshipments where it has been established that the catch has been taken in a manner which undermines the effectiveness of subregional, regional or global conservation and management measures on the high seas."

The PSM Agreement goes even further, as it "requires fishing vessels and vessels involved in fishing-related activities to provide a reasonable advance notice of their entry into port, a copy of their authorisations to fish, details of their fishing trip and quantities of fish on board." It also prescribes "inspections of foreign fishing vessels for the purpose of
This is a summary of: Fisheries Enforcement on the High Seas of the Arctic Ocean: Gaps, Solutions and the Potential Contribution of the European Union and its Member States

Accessible at: https://marxiv.org/gzvym

Author:

Efthymios Papastavridis

Added to MarXiv:

April 2018

Published: The International Journal of Marine and Coastal Law, 2018

Suggested Citation: Utilizing existing legal frameworks to implement fisheries management in the arctic. OCTO (2018). DOI: 10.17605/OSF.IO/HRB8G

See more MarXiv summaries at https://www.marxivinfo.org/ summaries

Across all disciplines, papers available for free with a preprint (also known as "Green OA") are cited $30 \%$ more than the world average (DOI: 10.7287/peerj. preprints.3119v1)

Share your research in MarXiv and the MarXiv Team may summarize it, just like this!

Step-by-step instructions on how to share your research in MarXiv are detailed at https://www.marxivinfo.org/ submission 
monitoring compliance with relevant conservation and management measures" and allows States to deny entry to ports of vessels suspected of violating fisheries management protocols. Some States, like Norway, even allow for criminal prison terms for foreign fishers who wilfully neglect fisheries management laws.

States may be inclined to deny the use of ports to vessels on the IUU Vessel List of regional fisheries management organizations, or after an inspection has revealed illegal activities. The EU's 2008 IUU Regulation created a Community IUU Vessel List, which must be regularly updated and made public. The List could be referenced by any port to ensure problematic vessels are not unloading illegally-harvested fish.

\section{Inspections on the high-seas}

The North-East Atlantic Fisheries Commission (NEAFC), which manages the "European wedge" of the Arctic, allows for member states to inspect fishery vessels of party States (and cooperating non-contracting parties) while on the high seas of the Arctic. Vessels of non-contracting party vessels may be asked to be inspected. If the captain does not consent, the vessel is automatically presumed to be engaging in IUU fishing. Together with Port-State Controls, there are effective legal mechanisms for fisheries enforcement on the high seas of the Arctic in the absence of an Arctic-wide regional fishery management organization.

* At the time the source paper was published, the draft text had not reached consensus. However, at the time of writing this summary, a consensus agreement has been reached. See https://oceanconservancy.org/blog/2018/03/07/central-arctic-ocean-next-steps-arcticsnewest-international-agreement/ for more information. Unfortunately, the exact text of this agreement is still being written. The final agreement's text will not likely be publicly available until the summer of 2018.
The MarXiv Team

Nick Wehner,

Director of Open Initiatives, OCTO

Raye Evrard,

Project Manager, OCTO

Allie Brown,

Project Associate, OCTO

Sarah Carr,

Chief Knowledge Broker,

ОСТO

John Davis,

President, OCTO

Correspondence

Nick Wehner

nick@octogroup.org

Financial support for MarXiv comes from the David and Lucile Packard Foundation.

The views expressed herein are those of the MarXiv Team and should not be interpreted as representing the opinions or policies of the Packard Foundation or other funders of MarXiv.

MarXiv is an ОстO Initiative

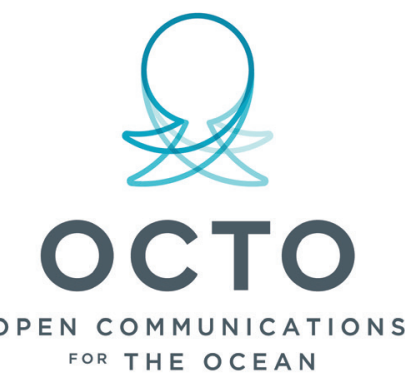

